\title{
Leptospirosis: a need for increased awareness and improved laboratory testing
}

\author{
Maness, L. R. \\ Clinical Laboratory Science Department, Winston-Salem State University, 304-D New Science Building, \\ 601 S. Martin Luther King Jr. Drive, Winston-Salem, North Carolina 27110, USA \\ Correspondence to: wishonl@wssu.edu; 336-750-8339 (work); 336-253-3677 (cell)
}

\begin{abstract}
:
While leptospirosis is currently described as an emerging pathogen, there have likely been numerous cases worldwide each year for centuries. Hurricanes and other flooding events contribute to its spread through rodent urine, many cases of which go undiagnosed. This is especially problematic in developing countries where laboratory techniques may be out of date. There are over 100 cases per year in the United States of America, but millions of cases occur worldwide annually. Caused by many different species of fastidious, spiral-shaped Leptospira, it is difficult and slow to culture. Strides have been made to improve culture techniques in order to reduce the time to grow this genus of bacteria. Greater understanding of this disease by laboratorians, physicians, and other healthcare workers and improved laboratory identification techniques will help increase diagnoses and decrease morbidity and mortality of leptospirosis.
\end{abstract}

Keywords: leptospirosis, hurricanes, emerging pathogen, zoonosis

Received Sept 2, 2021; Revised Oct 18, 2021; Accepted Oct 19, 2021; Published online Jan 18, 2022

Copyright 2022 AJCEM Open Access. This article is licensed and distributed under the terms of the Creative Commons Attrition 4.0 International License <a rel="license" href="http://creativecommons.org/licenses/by/4.0/", which permits unrestricted use, distribution and reproduction in any medium, provided credit is given to the original author(s) and the source. Editor-in-Chief: Prof. S. S. Taiwo

\section{Leptospirose: un besoin de sensibilisation accrue et d'amélioration des tests de laboratoire}

\author{
Maness, L. R. \\ Département des sciences de laboratoire clinique, Université d'État de Winston-Salem, 304-D Nouveau bâtiment \\ des sciences, $601 \mathrm{~S}$. Martin Luther King Jr. Conduire, Winston-Salem, Caroline du Nord 27110, États-Unis \\ Correspondance à: wishonl@wssu.edu; 336-750-8339 (travail); 336-253-3677 (portable)
}

\section{Résumé:}

Alors que la leptospirose est actuellement décrite comme un agent pathogène émergent, il y a probablement eu de nombreux cas dans le monde chaque année depuis des siècles. Les ouragans et autres inondations contribuent à sa propagation par l'urine de rongeurs, dont de nombreux cas ne sont pas diagnostiqués. Ceci est particulièrement problématique dans les pays en développement où les techniques de laboratoire peuvent être dépassées. Il y a plus de 100 cas par an aux Etats-Unis d'Amérique, mais des millions de cas surviennent chaque année dans le monde. Causée par de nombreuses espèces différentes de Leptospira fastidieux en forme de spirale, sa culture est difficile et lente. Des progrès ont été faits pour améliorer les techniques de culture afin de réduire le temps de croissance de ce genre de bactéries. Une meilleure compréhension de cette maladie par les laboratoires, les médecins et les autres professionnels de la santé et l'amélioration des techniques d'identification en laboratoire contribueront à augmenter les diagnostics et à réduire la morbidité et la mortalité de la leptospirose.

Mots clés: leptospirose, ouragans, pathogène émergent, zoonose 


\section{Introduction:}

Leptospirosis is caused by a variety of Leptospira species resulting in flu-like symptoms in addition to jaundice, red eyes, and rash (1). Some patients recover from this flu-like illness while others at first appear to recover but their symptoms then worsen after recovery. In some cases, liver or kidney damage, meningitis, respiratory distress, and even death occurs. About $10 \%$ of those with leptospirosis develop the severe form, and in those cases, the fatality rate is $5-15 \%(1)$.

Leptospirosis is the most widespread zoonotic infection in the world and is most common in the tropics and subtropics (2). It is considered emerging since there is increasing contact between humans and rodents that carry the pathogen (3). Human invasion of the natural habitats of zoonotic carriers and climate change, which results in local environmental changes, are believed to have altered the transmission rates of Leptospira sp $(2,3)$. Many cases follow hurricanes and other flooding events and are due to exposure of open wounds during cleanup efforts. More awareness is needed of the disease since many cases are likely missed. Fewer cases can be missed through increasing accessibility of laboratory testing.

\section{Epidemiology of leptospirosis}

In the United States, just over 100 cases are reported each year and about half of those are in Puerto Rico (1). The largest outbreak ever reported in the US was in 1998 where about 775 people were exposed to the disease, with 110 infected. Most of those infected were triathletes exposed at events held at Madison, Wisconsin and Springfield, Illinois a couple of weeks apart (4). The median age of the victims was 35 years, $76 \%$ were male, $66 \%$ sought medical care, and $32 \%$ were hospitalized. There was an outbreak of 81 U.S. marines training at the Jungle Warfare Training Center in Okinawa in 2014, likely due to drinking of stagnant water (5). An outbreak had previously occurred there among marines in 1987.

Leptospirosis was reported in Puerto Rico long before being reported after Hurricane Maria in 2017, especially correlating with periods of rainfall. This is likely because animal urines do not have the opportunity to saturate into the soil and are instead carried along in floodwaters to people who may not be wearing protective clothing and thus, become exposed (6). In 1996, leptospirosis was reported in Puerto Rico after Hurricane Hortense in September of that year. Four patients were susp- ected to have dengue fever, but tested negative, instead, they tested positive for Leptospira IgM antibodies. This caused the researchers to do a before and after comparison of dengue-negative Leptospira testing, and they found that 4 of 72 antisera from patients before the hurricane and 17 of 70 antisera from patients after the hurricane were positive for leptospirosis. The average positive patient was 34 years of age and male. It was then suggested that the disease is underreported due to absence of optimal testing, lack of physician awareness, and the similarity of symptoms to dengue. In this study, while many symptoms were similar to both dengue and leptospira, such as headache, rash, fever, and body pain, symptoms most specific to leptospira were eye and joint pain, diarrhea, and jaundice.

Just a couple of years later, Hurricane Mitch hit Honduras in 1998 and the incessant rains led to outbreaks of leptospirosis [7]. One study used Ellinghausen-McCullough-JohnsonHarris (EMJH) media and microscopic agglutinnation test (MAT) to determine the presence of pathogen in 68 samples, 24 of the samples had reactive MAT analysis and were speciated for Leptospira, the most common being Leptospira icterohaemorrhagiae. Most of the patients' reported rodents in or around their homes or contact with stagnant water, and many also claimed contact with their pets. Two cases of leptospirosis were reported among 48 people tested following a flood at a university in Oahu in 2004 (8), caused by a stream that overflowed following heavy rains. The first case, a 56-yearold patient had broken skin, and later blisters on his feet, while wading in the floodwaters and became ill with fever, chills, nausea, and vomiting about 10 days later. A few days later he had tremors, visual flashes, and poor balance. The second patient was a 27-year-old graduate student of the first patient and received a laceration to his foot during cleanup efforts. His symptoms began with nausea, vomiting, diarrhea, headache, fever, and chills 10 days after the flood. The second patient improved without treatment, while the first patient was hospitalized and later improved.

Leptospirosis became increasingly discussed recently due to Hurricane Maria. A debate pursued on whether or not cases of death from Leptospira sp. that occurred more than a month after the hurricane could be attributed to the storm itself $(9,10)$. About 26 deaths occurred due to Leptospira sp. within 6 months of the hurricane and only 4 were officially attributed to the disease if going by the one-month criteria. Several families argue that their family members were part of the hurricane clean-up and 
were not given prophylactic measures, protective gear, or warned about the disease and died days after the arbitrary one-month reporting cut-off.

Several recent studies have shown the worldwide abundance of the disease. One report reviewed 80 studies on the incidence of leptospirosis in 34 countries with some of the highest estimates of morbidity and mortality found in South and Southeast Asia, Oceania, Latin America, and East Sub-Saharan Africa (11). The study estimated 1.03 million cases and 58,900 deaths worldwide annually from leptospirosis, with many cases and deaths in males between the ages of 20 and 49 years. It was estimated in another study that almost 3 million disability adjusted life years (DALYs) are lost annually due to the greater than one million annual cases of leptospirosis, with males carrying around $80 \%$ of this burden (12). Additionally, most of this burden falls in developing countries of South and Southeast Asia, Western Pacific, Central and South America, and Africa.

Although leptospirosis is listed as endemic in Southeast Asia, Central and South America, the Caribbean, and Oceania, it was listed as probable endemic in Malaysia (13). A recent study indicated that Malaysia had 3,665 and 4,457 laboratory confirmed cases in 2012 and 2013, respectively. The overall age-standardized incidence rate was 29.02 per 100,000 and the most common age group was age 19 years or less, making up $23.3 \%$. The male to female ratio was 2.6:1. Students, agriculturebased, and plantation workers were among those most affected. The overall fatality rate was $1.47 \%$. Due to the results of the study, the authors stated that this is an emerging health concern in Malaysia and should be wellcontrolled.

Although it is suggested that the disease is emerging, it undoubtedly has existed far longer than the study indicates. In a similar study, it was reported that Mexico had 1,547 cases of leptospirosis between 2000 and 2001, with 198 recorded deaths (14). While findings did not indicate higher morbidity in males, the mortality was higher in males. Of total deaths from the disease, $61.1 \%$ were males during this time period. Whereas the case fatality rate was lower for the study in Malaysia than in many others, the cases in Mexico had a case fatality rate of $12.8 \%$.

\section{Laboratory identification of Leptospira}

Identification of Leptospira $\mathrm{sp}$ in the laboratory does not occur by using traditional methods of plating on blood, MacConkey, or chocolate agar plates. These spiral-shaped Gram-negative bacteria are fastidious and grow slowly even on broth media. Culture of this pathogen requires special nutrient media not included in the normal battery of media used in laboratories, which can be EMJH base media or whole blood or plasma $(15,16)$. Special media consisting of sodium pyruvate, superoxide dismutase, and/or fetal bovine serum has also been suggested (15).

The need for special culture requirements helps to explain why many cases are likely missed. Physicians would have to specifically order this test since the organism will not grow on routine media used when spinal fluid, urine, or blood cultures are ordered (17). The diagnosis is also missed often because the spirochete cannot be stained by the common Gram stain. A more sensitive stain must be used, such as immunofluorescent, immunohistochemical, or silver stain, which will have to be specifically ordered by the physician. The test ordered when a physician suspects a patient with leptospirosis, is often performed by a serological method such as enzyme-linked immunosorbent assay (ELISA) or MAT. These serological tests can be problematic for identification since during the early stages of the infection, antibodies may not be present in adequate numbers, resulting in false negatives.

Polymerase chain reaction (PCR) assay is increasingly being used to identify Leptospira and is usually positive from 5 to 15 days after the onset of disease (18). Leptospira serovars included in the database of matrix-assisted laser desorption/ionization time-of-flight mass spectrometry (MALDI-TOF-MS) $(18,19)$ has been shown to accurately and precisely identify multiple species of this pathogen. Many laboratories do not have the serovars included in their databases, since test for leptospirosis is not a routinely ordered test. However, including these serovars in MALDI-TOF may increase the likelihood of physicians ordering this test, but many developing countries where the disease is endemic do not have the financial resources for MALDI-TOF analyzer.

Susceptibility testing has not been traditionally performed on Leptospira sp. since culturing is time-consuming and currently there are no challenges of antibiotic resistance in leptospirosis. However, experimental attempts have been made to design appropriate growth media for detection of resistance that may occur in Leptospira population in the future. One such experimental study determined that the use of Noble agar base, in addition to $\mathrm{EMJH}$ base and enrichment with sodium pyruvate, $10 \%$ rabbit serum and increased $\mathrm{CO}_{2}$ increased the growth 
of Leptospira sp. better than other media tested (20). The other media tested were mixtures of bacteriological agar and various concentrations of rabbit serum as well as increasing $\mathrm{CO}_{2}$ at various concentrations (or not increasing it at all). Using this newly concocted Leptospira Vanaporn Wuthiekanun (LVW) agar, E-test could be performed after 7 days, with 2 days incubation as above, and 5 more days in ambient air at $30^{\circ} \mathrm{C}$. The authors felt this was a more rapid, simple, and cost-effective test that could be more widely used in tropical developing countries.

The disk diffusion susceptibility method was soon validated using this same LVW agar (21). Azithromycin, ceftriaxone, ciprofloxacin, doxycycline, gentamycin, and penicillin-G were all tested on 83 human species of Leptospira, which showed that all the species were sensitive to the 6 antibiotics, with large zones of inhibition. The median growth time on the LVW agar was 5 days, with some taking only 3 days and others taking up to 12 days to reach 4+ growth. This indicates that the newly adapted LVW agar could potentially be used to perform Kirby-Bauer testing on Leptospira if resistance arise.

The most recent study on improving Leptospira growth media was based on PCR analysis of the genome of the organism from culture growth, to determine what ingredients would best be included (22). After the results of genome analysis were obtained, the authors then included different ingredients into the culture media to determine which ingredient mixtures would result in the fastest growth. A mixture, dubbed M12, was found to grow various pathogenic and non-pathogenic species of Leptospira within 2 days, with the characteristic ring-like white layer. $\mathrm{M} 12$ media has specific compositions of $\mathrm{Na}_{2} \mathrm{HPO}_{4} 2 \mathrm{H}_{2} \mathrm{O}, \mathrm{KH}_{2} \mathrm{PO}_{4}$, tryptone, yeast extract, $\mathrm{KCl}$, aspartic acid, sodium pyruvate, glucose, $\mathrm{MgCl}_{2}$ anhydrous, $\mathrm{CaCl}_{2} .2 \mathrm{H}_{2} \mathrm{O}, \mathrm{NH}_{4} \mathrm{Cl}$, thiamine $\mathrm{HCl}$, sodium acetate, $\mathrm{NaHCO}_{3}$, casein, and water, at $\mathrm{pH}$ of 7.2. To have produced growth media with the ability to rapidly grow Leptospira sp. is a vast improvement that could lead to marked decreases in turnaround times for diagnoses as well as susceptibility testing if and when necessary. Further experiments with this media certainly seem warranted as does its use in identification in patient samples.

\section{Conclusion:}

Models that predict the effects of global warming on hurricanes vary (23-25). Some models report that global warming will increase the strength while others predict a weakening.
Either way, financial spending at coastlines is ever-increasing, indicating that cleanup after hurricanes will continue to increase (25). This increase will mean more cases of leptospirosis. Additionally, humans are continuing to encroach on natural lands where animals live and whose urine is present in the soil. The need for physicians, nurses, and laboratory workers to be aware of and understand the disease will ever be necessary, in order to reduce mortality and morbidity from leptospirosis in people working in and around floodwaters. Additionally, in areas with hurricane and flooding activity, especially in developing countries, there is need to increase laboratory testing abilities for identifying Leptospira sp. Countries that cannot afford more expensive molecular methods of identification should at minimum have updated culture methods in place that can more rapidly identify this deadly pathogen.

\section{References:}

1. Centers for Disease Control and Prevention. Leptospirosis. 2019.

https://www.cdc.gov/leptospirosis/index.html

2. Guerra, M. A. Leptospirosis: public health perspectives. Biologicals. 2013; 41: 295-297.

3. Vijayachari, P., Sugunan, A. P., and Shiram, A. N. Leptospirosis: an emerging global public health problem. J Biosci. 2008; 33: 557-569.

4. Centers for Disease Control and Prevention. Update: Leptospirosis and unexplained acute febrile illness among athletes participating in triathlonsIllinois and Wisconsin, 1998. MMWR Weekly Rep. 1998; 47: 673-676.

5. Dierks, J., Servies, T., and Do, T. A study on the leptospirosis outbreak among U.S. marine trainees in Okinawa, Japan. Military Medicine. 2018; 183: e208- e2012.

6. Sanders, E. J., Rigau-Perez, J. G., Smits, H. L., et al. Increase in leptospirosis in dengue-negative patients after a hurricane in Puerto Rico in 1996. Am J Trop Med Hyg. 1999; 61: 399-404.

7. Naranjo, M., Suarez, M., Fernandez, C., et al. Study of a leptospirosis outbreak in Honduras following hurricane Mitch and prophylactic protection of the

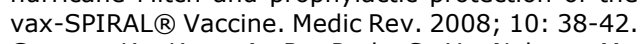

8. Gaynor, K., Katz, A. R., Park, S. Y., Nakata, M., Clark, T. A., and Effler, P. V. Leptospirosis on Oahu: an outbreak associated with flooding of a university campus. Am J Trop Med Hyg. 2007; 76: 882-885.

9. Sutter, J. D. Deaths from bacterial disease in Puerto Rico spiked after Maria. CNN Health 2013. https://www.cnn.com/2018/07/03/health/sutterleptospirosis-outbreak-puerto-rico-invs/index.html.

10. Reily, $H$. Dozens died from treatable illness in Puerto Rico after Maria. Axios Media. 2018. https://www.axios.com/leptospirosis-puerto-ricohurricane-maria-deaths-53bdaa95-7b91-4e72bcdc-29c96b521d7a.html.

11. Costa, F., Hagan, J. E., Calcagno, J., et al. Global morbidity and mortality of leptospirosis: a systematic review. PLOS Negl Trop Dis. 2015: 1-19.

12. Torgerson, P. R., Haga, J. E., Costa, F., et al. Global burden of leptospirosis: estimated in terms of disability adjusted life years. PLOS Negl Trop Dis. 2015; 10: 1-14. 
13. Tan, W. L., Soelar, S. A., Sua, M. A., et al. Leptospirosis incidence and mortality in Malaysia. Acta Trop. 2016; 47: 434-440.

14. Sanchez-Montes, S., Espinosa-Martinez, D. V., Rios-Munoz, C. A., Berzunza-Cruz, M., and Becker, I. Leptospirosis in Mexico: epidemiology and potential distribution of human cases. PLoS One. 2015; 10: 1-16.

15. Chideroli, R. T., Goncalves, D. D., Suphoronski, S. A., et al. Culture strategies for isolation of fastidious serovar Hardjo and molecular differentiation of genotypes hardjobovis and hardjoprajitno. Front Microbiol. 2017; 8: 2155.

16. Wuthiekanun, V., Chierakul, W., Limmathurotsakul, D., et al. Optimization of culture of leptospira from humans with leptospirosis. J Clin Microbiol. 2007; 45: 1363-1365.

17. Musso, D., and La Scola, B. Laboratory diagnosis of leptospirosis: a challenge. J Microbiol Immunol. 2013; 46: 245-252.

18. Djelouadji, Z., Roux, V., Raoult, D., Kodjo, A., and Drancourt, M. Rapid MALDI-TOF mass spectrometry identification of Leptospira organisms. Vet Microbiol. 2012; 158: 142-146.

19. Calderaro, A., Piccolo, G., Gorrini, C., et al. Leptospira species and serovars identified by
MALDI-TOF mass spectrometry after database implementation. BMC Res Notes. 2014; 7: 330.

20. Wuthiekanum, V., Amornchai, P., Paris, D., et al. Rapid isolation and susceptibility testing of Leptospira spp. using a new solid medium LVW agar. Antimicrob Agents Chemother. 2013; 57: 297-302.

21. Boss, J., Dance, D., Chanthongthip, A., Newton, P., Wuthiekanun, V, and Robinson, M. Antimicrobial susceptibility testing of Leptospira sp. in the Lao People's Democratic Republic using disk diffusion. Am J Trop Med Hyg. 2019; 100: 1073-1078.

22. Dhayabaran, V., Chidambaram, D., and Krishnaswamy, P. Identification of compounds for improved growth of Leptospira in culture and isolation. Diagn Microb Infect Dis. 2020; 96: 1-8.

23. Emanuel, K. Global warming effects on U.S. hurricane damage. Amer Meteorol Soc. 2011; 3: 261-268.

24. Trenberth, K. Uncertainty in hurricanes and global warming. Science. 2005; 308: 1753-1754.

25. Nordhaus, W. D. The economics of hurricanes and implications of global warming. Clim Chang Econ. 2010; 1: 1-20. 